human alimentary tract within the first few days of life. This organism has also been shown to be responsible for disease characterised by bloody diarrhoea, patchy intestinal necrosis, and penumatosis intestinalis both in man and in the newborn of other species. Unfortunately, the primary lethal necrotising exotoxins of $C$ perfringens may prove difficult to detect after their production in vivo. With the exception of the lecithinase and haemolysis tests for alpha toxin, there are no reliable in vitro tests for these primary lethal toxins. Furthermore, certain toxins may be readily destroyed by trypsin or fixed to tissue, thus hindering detection in faecal contents. Our failure to detect free alpha toxin in the stools of babies with NEC may genuinely reflect its lack of involvement in the disease process. It is also possible that toxin produced locally at a site of necrosis is rapidly broken down or fixed to tissue and is for these reasons undetectable in intestinal content.

D F M Thomas was supported by a Wellcome Trust Surgical Fellowship. The authors thank the neonatal physicians and surgeons who generously cooperated in this study. In addition to the hospitals mentioned in the text, samples were provided by neonatal intensive care units at the Children's Hospital, Birmingham, Guys Hospital, London, Kingston Hospital, Surrey, St
James's University Hospital, Leeds, 'I he City Hospital, Nottingham, and The Children's Hospital, Sheffield.

\section{References}

${ }^{1}$ Batty I. In: Norris JR, Ribbons DW, eds. Methods in microbiology. Vol. 5A. London and New York: Academic Press, 1971:271-3.

${ }^{2}$ Chang TW, Areson P. Neonatal necrotizing enterocolitis: absence of enteric bacterial toxins (letter). $N$ Engl J Med 1978;299:424.

3 Stoll BJ, Nahmias AJ, Wickliffe C, Brann AW, Jr, Dowell VR, $\mathrm{Jr}$, Whaley DN. Bacterial toxin and neonatal necrotizing enterocolitis. $J$ Pediatr 1980;96:114-5.

${ }^{4}$ Cashore WJ, Peter G, Lauermann M, Stonestreet BS, Oh W. Clostridia colonization and clostridial toxin in neonatal necrotizing enterocolitis. J Pediatr 1981;98:308-11.

5 Donta ST, Myers MG. Clostridium difficile toxin in asymptomatic neonates. J Pediatr 1982;100:431-4.

${ }^{6}$ Sherertz RJ, Sarubbi FA. The prevalence of clostridium difficile and toxin in a nursery population: a comparison between patients with necrotizing enterocolitis and an asymptomatic group. J Pediatr 1982;100:435-9.

7 Thomas DFM, Fernie DS, Malone M, Bayston R, Spitz L. Association between clostridium difficile and enterocolitis in Hirschsprung's disease. Lancet 1982;i:78-9.

Correspondence to Mr D F M Thomas, Regional Neonatal Surgical and Medical Intensive Care Unit, Clarendon Wing, The General Infirmary at Leeds, Belmont Grove, Leeds LS2 9NS.

Received 10 November 1983

\title{
Increased vomiting induced by an antiemetic drug
}

\author{
M SINAASAPPEL, W J DEN OUDEN, I LUYENDIJK, AND H J DEGENHART \\ Department of Paediatrics, Erasmus University and University Hospital Rotterdam, Sophia Children's \\ Hospital, and Ikazia Hospital Rotterdam, the Netherlands
}

SUMMARY A case of progressive vomiting in a boy aged 5 months is reported. Vomiting was secondary to an obstruction in the antrum of the stomach caused by a mass consisting of alginate.

Vomiting in infants may be caused by various stomach disorders. As the illness is often transient it is commonly treated symptomatically with further investigation reserved for persistent cases only. The following case history shows, however, that symptomatic treatment may lead to further problems.

\section{Case report}

A boy aged 5 months was referred with suspected gastro-oesophageal reflux as the cause of his persistent vomiting, which had been present from the very first days of life. Initially, his physical development had been normal, but from week 16 onwards his body weight had not increased and traces of blood were occasionally found in the vomitus. Symptomatic treatment with Nutriton, (a food thickening agent, dosage two to three measures/feed) had been unsuccessful, as were Motilium (domperidon) (6 $\mathrm{mg} /$ day), and Gaviscon ( $15 \mathrm{ml} /$ day). Radiocontrast studies performed a few days before referral had failed to show either diaphragmatic hernia or gastro-oesophageal reflux. Gastric emptying was normal and no foreign matter was seen in the stomach.

Further investigation was requested including determination of oesophageal $\mathrm{pH}$ and endoscopic studies of the oesophagus and stomach. To our 


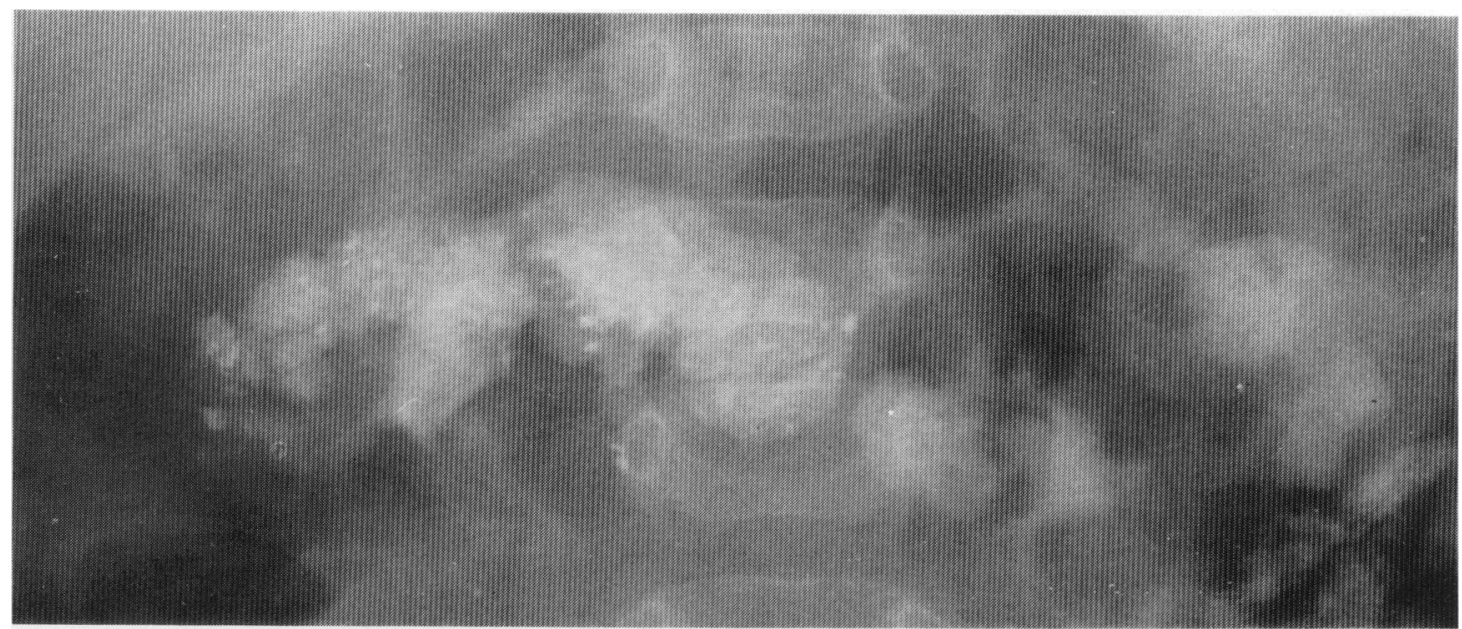

Figure Remnants of the bezoar in the proximal gut after endoscopic fragmentation.

amazement, gastroscopic examination showed a gelatinous mass filling the antrum and blocking the passage to the pylorus. After fragmentation most of the mass was removed with the gastroscope and the remaining particles were pushed through the pylorus (Figure). No evidence of diaphragmatic hernia or reflux oesophagitis was found. After the intervention the patient's condition improved and vomiting gradually stopped. He is now 1 year old and free from symptoms.

Investigation of the mass showed traces of silicon, magnesium, and aluminium. After hydrolysis, we found a strongly positive reaction with carbazole indicating the presence of a polyhexuronic acid. ${ }^{1}$ Gaviscon produced the same reaction.

\section{Discussion}

Several types of bezoar occur in childhood: the trichobezoar (hairball) has been known of old, but in recent years various patients have been described with signs of obstruction which seemed to be caused by inspissated milk and lactobezoars. The latter occur mainly in preterm infants who are maintained on highly concentrated, continuous drip nutrition, and particularly when there is insufficient hydration. ${ }^{2}$ Our patient was bottle fed on a normal formula and was not dehydrated.

The occurrence of bezoars secondary to medication in infants has only rarely been described. Recently a few cases were reported of bezoars caused by polystyrene resin ${ }^{34}$ and aluminium hydroxide. ${ }^{5}$ These patients were neonates and all in a poor condition with symptoms of renal insuf- ficiency. By contrast, our patient was a 5 month old baby, without any signs of renal insufficiency. Delayed stomach emptying has also been suggested as a contributing factor in the occurrence of bezoars, but our patient was being treated with domperidon, which in fact stimulates the emptying of the stomach.

Gaviscon was the most probable cause of the obstruction in our patient, but although it contains aluminium hydroxide as well as magnesium trisilicate, analysis of the bezoar showed only traces of aluminium and magnesium and it is unlikely, therefore, that these metals were the cause. The active ingredient of Gaviscon is the combination alginic acid/antacid. In the stomach the carboxyl groups of alginic acid react with sodium bicarbonate to form a soluble alginate. In this way carbon dioxide is released and a froth is produced. The material, which is comparatively light and has a high viscosity, produces a coating on the contents of the stomach remaining in the proximity of the gastrooesophageal junction. Alginic acid is a polyhexuronic acid and will react wiith carbazole. The fact that our patient had a mass in his stomach also showing a positive reaction with carbazole suggests that the mass was derived from the alginate present in Gaviscon. A similar occurrence was described some years ago by Hewitt; ${ }^{6}$ in that case an overdose of Gaviscon (10 times the normal dose) in a neonate resulted in a 'Gavisconoma' in the stomach. Our patient, however, received a normal dosage. We surmise that the combination of the two drugs (Nutriton and Gaviscon) may have resulted in a precipitate producing a mass. 
The reason for the patient's persistent vomiting in the first five months of life may well have been a slower development of his antireflux mechanism, but we have not been able to confirm this hypothesis.

\footnotetext{
References

${ }^{1}$ O'Brien D, Rodgerson DO, Ibbott FA. Laboratory manual of pediatric micro- and ultramicro biochemical techniques. 4th ed. New York: Harper \& Row, 1968:231.

2 Schreiner RL, Lemons JA, Gresham EL. A new complication of nutritial management of the low-birth-weight infant. Pediatrics 1979;63:683-4.
}

${ }^{3}$ Menke JA, Stallworth RE, Bindstadt DH, Strano AJ, Wallace SE. Medication bezoar in a neonate. Am J Dis Child 1982;136:72-3.

${ }^{4}$ Metlay LA, Klionsky BC. An unusual gastric bezoar in a newborn: polystyrene resin and candida albicans. $J$ Pediatr 1983;102:121-3.

5 Portuguez-Malavasi A, Aranda JV. Antacid bezoar in a newborn. Pediatrics 1979;63:679 80.

${ }^{6}$ Hewitt GJ, Benham ES. A complication of gaviscon in a neonate-'the gavisconoma'. Aust Paediatr J 1976;12:47-8.

Correspondence to Dr M Sinaasappel, Department of Paediatrics, Gastro-enterological Division, Erasmus University and University Hospital, Rotterdam, The Netherlands.

Received 7 November 1983

\title{
Intrahepatic cysts in biliary atresia after successful hepatoportoenterostomy
}

\author{
S SAITO, T NISHINA, AND Y TSUCHIDA \\ Department of Paediatric Surgery, University of Tokyo, Japan
}

SUMMARY A patient with an unusual association of biliary atresia and two intrahepatic cysts is reported. The infant was treated by a hepatoportoenterostomy at 2 months of age and by subsequent drainage of the cysts at 13 months. These cysts were detected by ultrasound during a febrile illness.

A boy who had extrahepatic biliary atresia and two solitary intrahepatic cysts was successfully treated by hepatoportoenterostomy and by external drainage of the cysts.

\section{Case report}

A boy, born at term in November 1979, had neonatal hyperbilirubinaemia and underwent phototherapy on the third day of life. Jaundice did not resolve, however, and the infant began to pass acholic stools. On physical examination the sclerae and skin were icteric. Laboratory investigations showed: total protein, $52 \mathrm{~g} / \mathrm{l}$; albumin, $34 \mathrm{~g} / \mathrm{l}$; total bilirubin, $121.4 \mu \mathrm{mol} / 1$ ( $7.1 \mathrm{mg} / \mathrm{dl})$; direct bilirubin, $92.3 \mu \mathrm{mol} / 1(5.4 \mathrm{mg} / \mathrm{dl})$; serum glutamic oxalo-acetic transaminase, $54 \mathrm{IU}$; serum glutamic peruvate transaminase, $37 \mathrm{IU}$; lactate dehydrogenase, 271 IU; alkaline phosphatase, 310 IU.

Laparotomy performed at 56 days of age showed a cystically dilated choledochus and an atrophic gall bladder. An operative cholangiogram showed a cystic choledochus without any communication into the duodenum or intrahepatic bile ducts. The dilated and cord like portions of the extrahepatic bile ducts were totally resected and a hepatoportoenterostomy ${ }^{1}$ was performed, leaving the distal end of the jejunal loop as a complete external fistula ${ }^{2}$ converted to internal drainage three weeks after the initial surgery. Histological examination showed biliary atresia.

The infant did well for the next 6 months, although he did have several transient fevers which were quickly resolved with antibiotics. His serum bilirubin concentration at this time was $15.4 \mu \mathrm{mol} / \mathrm{l}$ $(0.9 \mathrm{mg} / \mathrm{dl})$. At the age of $12 \mathrm{months}$, an abdominal ultrasound examination was performed during an episode of fever. Two cystic spaces, $1.75 \mathrm{~cm} \times 2.5$ $\mathrm{cm}$ on the right and $1.2 \mathrm{~cm} \times 2.0 \mathrm{~cm}$ on the left, were identified within the parenchyma at the porta hepatis. Percutaneous transhepatic cholangiography clearly showed two separate solitary cysts (Fig. 1) which did not communicate with the hepatic ducts, with the hepatojejunal loop, or with each other. The right cyst contained yellowish fluid (total bilirubin, $25.6 \mu \mathrm{mol} / 1(1.5 \mathrm{mg} / \mathrm{dl}))$ and the left one clear fluid (total bilirubin, $1.7 \mu \mathrm{mol} / 1(0 \cdot 1 \mathrm{mg} / \mathrm{dl})$. An ultrasound scan performed two weeks later showed that the cysts had enlarged-the right one to 4.0 $\mathrm{cm} \times 5.0 \mathrm{~cm}$, and the left one to $2.0 \mathrm{~cm} \times 5.0 \mathrm{~cm}$ (Fig. 2).

A third laparotomy was performed in December 1980. The right cyst was located behind the hepatojejunal loop, but dye injected into it failed to show communication with the loop. The cyst walls were opened and Penrose drains to the abdominal wall 